\title{
The RET C611Y mutation causes MEN 2A and associated cutaneous lichen amyloidosis
}

\author{
Xiao-Ping Qi', *, Jian-Zhong Peng ${ }^{2, *}$, Xiao-Wei Yang ${ }^{3}$, Zhi-Lie Cao ${ }^{1}$, Xiu-Hua Yu', Xu-Dong Fang ${ }^{1}$, \\ Da-Hong Zhang ${ }^{4}$ and Jian-Qiang Zhao ${ }^{5}$ \\ 1Department of Oncologic and Urologic Surgery, The 117th PLA Hospital, Wenzhou Medical University, Hangzhou, Zhejiang Province, China \\ 2Department of Dermatology, Hangzhou Third People's Hospital, Hangzhou, Zhejiang Province, China \\ ${ }^{3}$ Department of Pediatrics, The First People's Hospital of Wenling City, Wenling, Zhejiang Province, China \\ ${ }^{4}$ Department of Urologic Surgery, Zhejiang Provincial People's Hospital, People's Hospital of Hangzhou Medical College, Hangzhou, Zhejiang \\ Province, China \\ ${ }^{5}$ Department of Head and Neck Surgery, Zhejiang Cancer Hospital, Hangzhou, Zhejiang Province, China
}

Correspondence should be addressed to Xiao-Ping Qi or Jian-Qiang Zhao or Da-Hong Zhang: qxplmd@163.com or zhaojianqiang73@163.com or zhangdahong88@126.com

*(X-P Qi and J-Z Peng contributed equally to this work)

\begin{abstract}
Background: Cutaneous lichen amyloidosis (CLA) has been reported in some multiple endocrine neoplasia type 2A (MEN 2A) families affected by specific germline RET mutations $\mathrm{C} 634 \mathrm{~F} / \mathrm{G} / \mathrm{R} / \mathrm{W} / \mathrm{Y}$ or V804M, as a characteristic of the clinical manifestation in 'MEN 2A with CLA', one of four variants of MEN 2A, which was strictly located in the scapular region of the upper back.

Patient Findings: This study reports a large south-eastern Chinese pedigree with 17 individuals carrying the MEN 2A-harboring germline C611Y (c.1832G>A) RET mutation by Sanger sequencing. One individual presented MEN 2A-related clinical features, including typical CLA in the interscapular region; another individual exhibited neurological pruritus and scratching in the upper back but lacked CLA skin lesions. Both subjects presented with CLA or pruritic symptoms several years before the onset of medullary thyroid carcinoma (MTC) and/or pheochromocytoma. The remaining 15 RET mutation carriers did not exhibit CLA; of these, one presented with MTC and pheochromocytoma, nine with MTC only, two with elevated serum calcitonin and three younger subjects with normal serum calcitonin levels. This family's clinical data revealed a later diagnosis of MTC (mean age, 45.9 (range: 23-73) years), a lower penetrance of pheochromocytoma $(2 / 17,11.8 \%)$ and CLA (1/17, 5.9\%). However, no hyperparathyroidism and Hirschsprung disease were reported in this family.

Summary and Conclusions: This is the first description of a family with MEN 2A-related CLA due to a germline RET C611Y mutation, which might exhibit a novel and diversified genotype-phenotype spectrum in MEN 2A.
\end{abstract}
Key Words
- multiple endocrine neoplasia type $2 \mathrm{~A}$
- medullary thyroid carcinoma
- cutaneous lichen amyloidosis
- RET proto-oncogene
- C611Y mutation

Endocrine Connections (2018) 7, 998-1005

\section{Introduction}

Cutaneous lichen amyloidosis (CLA) is a rare skin disease occasionally detected in multiple endocrine neoplasia type 2A (MEN 2A). Initially, the presence of CLA was observed in patients with MEN 2A, who were explicitly related to codon 634 germline mutations in exon 11 of RET proto-oncogene; this mutation locates in the extracellular cysteine-rich region of the RET protein. CLA in MEN 2A is exclusively located in the scapular

$$
\begin{array}{lr}
\text { http://www.endocrineconnections.org } & \text { () } 2018 \text { The authors } \\
\text { https://doi.org/10.1530/EC-18-0220 } & \text { Published by Bioscientifica Ltd }
\end{array}
$$


region of the upper back, corresponding to dermatomes T2-T6 (1, 2, 3, 4, 5, 6, 7). Reportedly, the following two germline mutations exist in intracellular tyrosine kinase domains: the RET V804M mutation within exon 14 in an American female with medullary thyroid carcinoma (MTC) and CLA on the upper back (8) and the RET S891A mutation within exon 15 binding OSMR variant G513D in a Chinese familial MTC (FMTC) family with cutaneous biphasic amyloidosis comprising the lower legs to thighs, upper back, shoulders, arms and forearms (9).

The recurring extracellular C611Y germline mutation within exon 10 of $R E T$ has been regularly reported to associate with MTC, pheochromocytoma (PHEO) and hyperparathyroidism (HPT), but the absence of CLA and Hirschsprung disease $(3,4,5,10,11,12,13,14,15,16,17$, $18,19)$. This study reports a south-eastern Chinese Han MEN 2A family with CLA, which was caused by the RET C611Y germline mutation, offering a novel insight into the genotype-phenotypic spectrum in MEN 2A.

\section{Subjects and methods}

\section{Participants}

The study was approved by the Ethical Committees of the 117th PLA Hospital. In this study, we examined a five-generation southern Chinese pedigree with MEN 2A from Fujian Province, China, at Jian'ou Municipal Hospital (Fujian, China), the 117th PLA Hospital and Zhejiang Cancer Hospital (Zhejiang, China) between April 1988 and September 2017 (Fig. 1). We obtained written informed consent from all participants and/or their legal guardians, as required by the Ethical Committees of the 117th PLA Hospital.

\section{Clinical approach}

We obtained clinical profiles, surgical procedures, preoperative and postoperative biochemical data, imaging examinations and follow-up records. On the basis of the published criteria, we clinically and biochemically examined 39 members of this family $(4,5,9,20)$. The biochemical examination comprised basal serum calcitonin (Ctn) by the chemiluminescence assay (normal males, $<8.4 \mathrm{pg} / \mathrm{mL}$; females, $<5.0 \mathrm{pg} / \mathrm{mL}$; Immulite 2000 Immunoassay System; Siemens Ltd), parathyroid hormone (PTH; normal, 15-65 ng/mL), carcinoembryonic antigen (CEA; normal, $<5.0 \mathrm{ng} / \mathrm{mL}$ ) by electrochemiluminescent immunoassays (Elecsys analyzer, Roche Diagnostics $\mathrm{GmbH}$ ), plasma catecholamine (normal, <100 ng/mL (norepinephrine); $\quad<600 \mathrm{pg} / \mathrm{mL} \quad$ (dopamine); and $<100 \mathrm{ng} / \mathrm{mL}$ (epinephrine)) by radioimmunoassay or metanephrin (normal, $<62 \mathrm{ng} / \mathrm{mL}$ ) and normetanephrin (normal, $<145 \mathrm{ng} / \mathrm{mL}$ ) by liquid chromatographic tandem mass spectrometry (AB Sciex 4500MD LC/MS/MS; GenTech Scientific, New York, NY, USA), serum calcium by the arsenazo III method (Hitachi 7180 Biochemistry Analyzer; Hitachi). In addition, we performed slit lamp examination. The imaging examinations comprised thyroid ultrasound (US), CT, adrenal gland and parathyroid gland nuclear MRI, CT and/or emission CT (ECT), if indicated.

\section{RET mutation analysis}

We extracted the genomic DNA from the peripheral blood per the manufacturer's instructions (Qiagen, Hilden, Germany). In addition, the PCR amplification of each entire exon of the RET proto-oncogene was performed, followed by direct bidirectional DNA sequencing with the ABI Prism 3700 automatic sequencer (Perkin-Elmer) $(7,9)$.
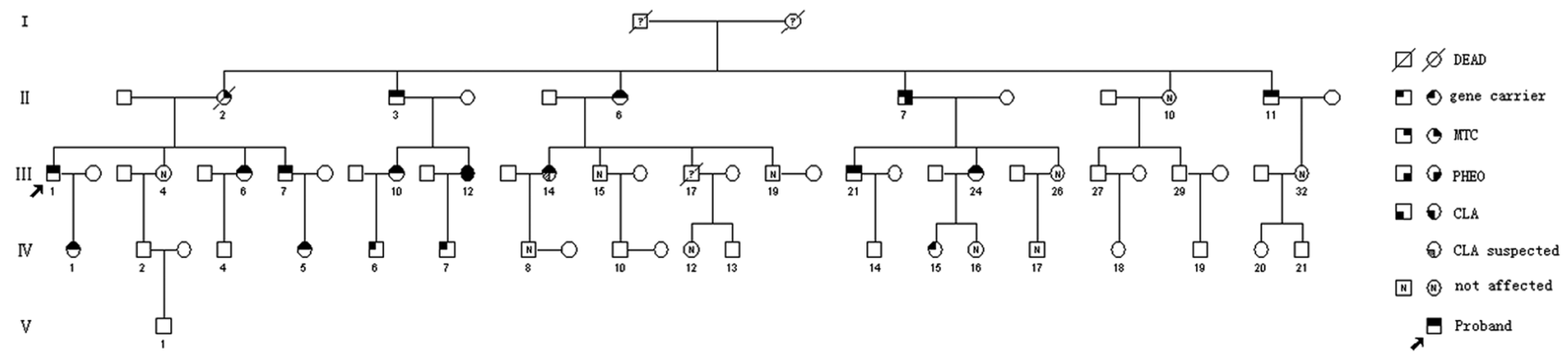

Figure 1

Pedigree of the southern five-generation Chinese family members with MEN 2A associated with CLA and the RET C611Y mutation. Circles and squares, female (F) and male (M) family members, respectively. CLA, cutaneous lichen amyloidosis; MTC, medullary thyroid carcinoma; PHEO, pheochromocytoma. Slashes, deceased subjects. All the numbered subjects are those who underwent clinical evaluation and/or RET screening.

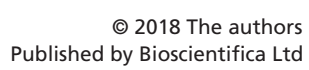

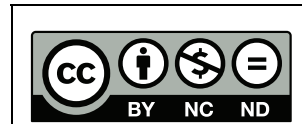

This work is licensed under a Creative Commons Attribution-NonCommercial-NoDerivatives 4.0 International License. 


\section{Histopathological analysis}

We confirmed the diagnosis of MTC, PHEO and CLA by a histopathological examination (Leica DM1000 biological microscope; Leica). In addition, we performed the tumor staging according to the American Joint Committee on Cancer (7th edition) tumor-node-metastasis (TNM) classification system (21). The skin biopsy specimen was obtained from the cutaneous lesions of one subject (III:12), fixed in 10\% buffered formalin and embedded in paraffin wax. Furthermore, we used haematoxylin-eosin, Congo red and crystal violet (Solaibao, Beijing, China) staining to $4 \mu \mathrm{m}$ thick sections $(1,6,7,22,23,24)$.

\section{Results}

\section{Clinical features and phenotypic data}

\section{Patients with MTC and PHEO}

Based on five-generation family medical history investigation, the results revealed post-operation histopathological findings showed that of seven patients, 6 (II:2, proband/ III:1, III:7, III:10, III:14, IV:5) had only MTC, but another (III:12) presented MTC and right PHEO. (Fig. 1 and Table 1). In 2017, we further performed biochemical testing, imaging studies and/or RET screening on all family members, except one (II:2; Table 1). Overall, 22 members exhibited normal Ctn levels and US images, and 17 (II:3, II:6, II:7, II:11, III:1, III:6, III:7, III:10, III:12, III:14, II:21, III:24, IV:1, IV:5, IV:6, IV:7 and IV:15) exhibited the RET C611Y mutation. Then, of 11 newly enrolled subjects, 10 underwent surgery, except 1 (III:6, 56 years) who presented with higher elevated Ctn (1326.3pg/mL) and CEA (20.08ng/mL) and multicentric hypoechoic nodules (left, $0.8 \mathrm{~cm}$; right, $2.5 \mathrm{~cm}$; T2NxMx) with calcifications in both thyroid lobes. In addition, two subjects (II:3 and II:11) exhibited increased Ctn levels (247.8 and $356 \mathrm{pg} / \mathrm{mL}$ ) who underwent total thyroidectomy with bilateral level VI lymph node dissection and modified bilateral neck dissection. The histopathological examination revealed bilateral MTC with lymph node metastasis (T1aN1aM0 and T1bN1bM0). Furthermore, five subjects (II:6, II:7, III:21, III:24 and IV:1) exhibited slightly elevated Ctn levels (range, 9.87-41.5 pg/mL); of these, three (II:6, II:7 and IV:1) accepted and underwent total thyroidectomy with bilateral level VI lymph node dissection, and one (II:7) presented with right PHEO $(2.6 \mathrm{~cm} \times 1.6 \mathrm{~cm} \times 1.0 \mathrm{~cm})$ and slightly increased serum metanephrin and normetanephrin but lack of clinical symptoms, who underwent laparoscopic right adrenalsparing surgery 2 weeks before the initial thyroid surgery. The histopathological examination confirmed bilateral MTC in all (T1aNOM0) and right PHEO in one (II:7). Another two subjects (III:21 and III:24) agreed to undergo scheduled thyroidectomy later (might have had MTC or C cell hyperplasia). Of note, three younger carriers (IV:6, IV:7 and IV:15) presented no abnormal Ctn/CEA values and imaging manifestation and selected a watchful waiting approach. Besides, six patients presented before the RET mutation screening as follows: 2 subjects (III: 1 and III:12) presented with increased Ctn and CEA (211 and $1417.9 \mathrm{pg} / \mathrm{mL} ; 14.48$ and $37.48 \mathrm{ng} / \mathrm{mL}$, respectively) and thyroid nodules (2.8 and $2.5 \mathrm{~cm}$, respectively) with calcifications in left/both thyroid lobes. Fortunately, the ECT examination revealed no distant metastases. Consequently, they underwent left/ total thyroidectomy with modified bilateral neck dissection. Histopathology revealed left or bilateral MTC with lymph node metastases (T2N1bM0). Moreover, three subjects (III:7, III:10 and III:14) presented with a slightly elevated Ctn (range, $5.42-48.3 \mathrm{pg} / \mathrm{mL}$ ) and/or residual thyroid lobes with local enlarged cervical nodules $(<1.3 \mathrm{~cm})$. Thus, a much more careful watch is warranted. Notably, one subject (IV:5) still had consistently undetectable Ctn and provided no evidence of abnormality after initial thyroidectomy (Table 1).

\section{Patients with CLA}

Of all 17 individuals with the RET mutation, 1 (5.9\%) was diagnosed (III:12) with CLA by a dermatologist, 1 $(5.9 \%)$ with regional pruritus and scratching without other typical CLA signs (III:14), and none of the other 15 affected relatives presented with pruritus or skin lesions. During the investigation, we stumbled upon an unexpected discovery in 2017. During a routine comprehensive medical history enquiry, two subjects (III:12 and III:14) recounted an intractable but episodic pruritus with the recurrent scratching of the interscapular region, accompanied by a burning sensation occasionally since the age of 22 years or 20s, respectively. Their itch worsened under periods of stress and dry weather. Although glucocorticoid ointment provided incomplete symptom relief of pruritus, it reappeared following the dose reduction. The physical examination revealed that one (III:12) presented with evident cutaneous lesions with brown, hyperpigmented, dry, scaly and thickened papules on the skin with scabby scratches located in the interscapular central region at the T2-T6 level (Fig. 2A). A subsequent skin lesion biopsy and the histological pattern revealed characteristic features of CLA in the skin lesion (Fig. 2B, C and D). However, the other (III:14), who only presented with cutaneous scabby scratches, remained undecided about a skin lesion biopsy (not shown).

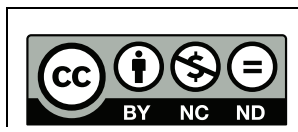

This work is licensed under a Creative Commons Attribution-NonCommercial-NoDerivatives 4.0 International License. 

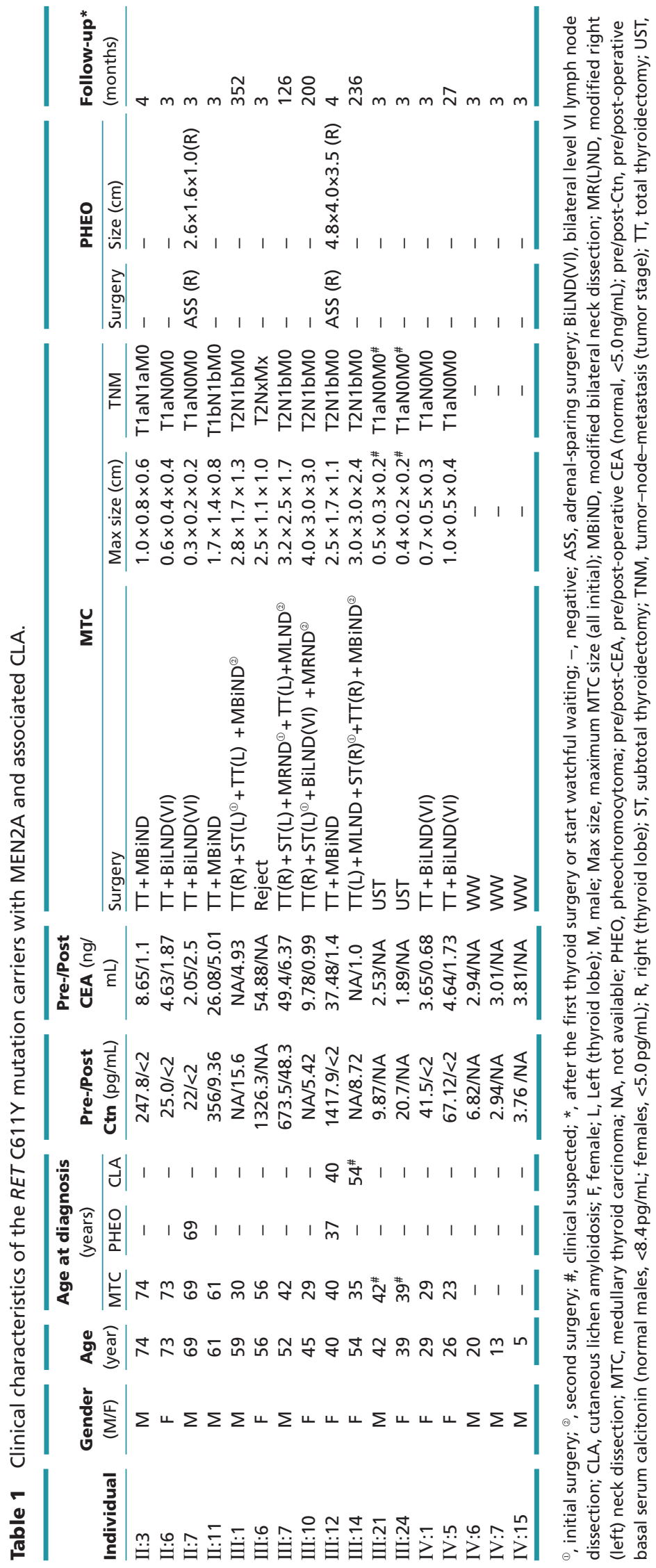

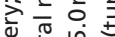

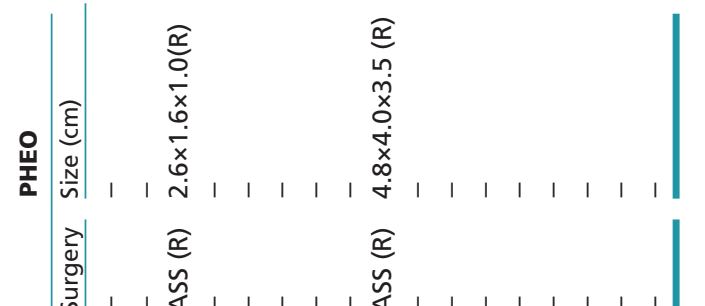

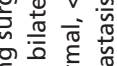

要

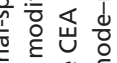

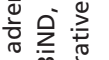

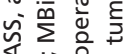

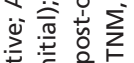

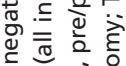

个. 出

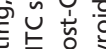

$\sum_{\varepsilon} \frac{2}{d} \frac{1}{2}$

至

年

t啇

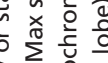

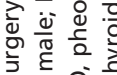

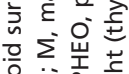

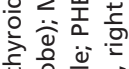

蒙高 $\frac{0}{0}$

至金范

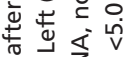

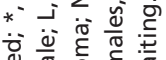

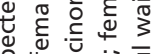

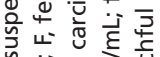

정

至

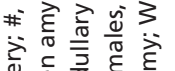

它 它 

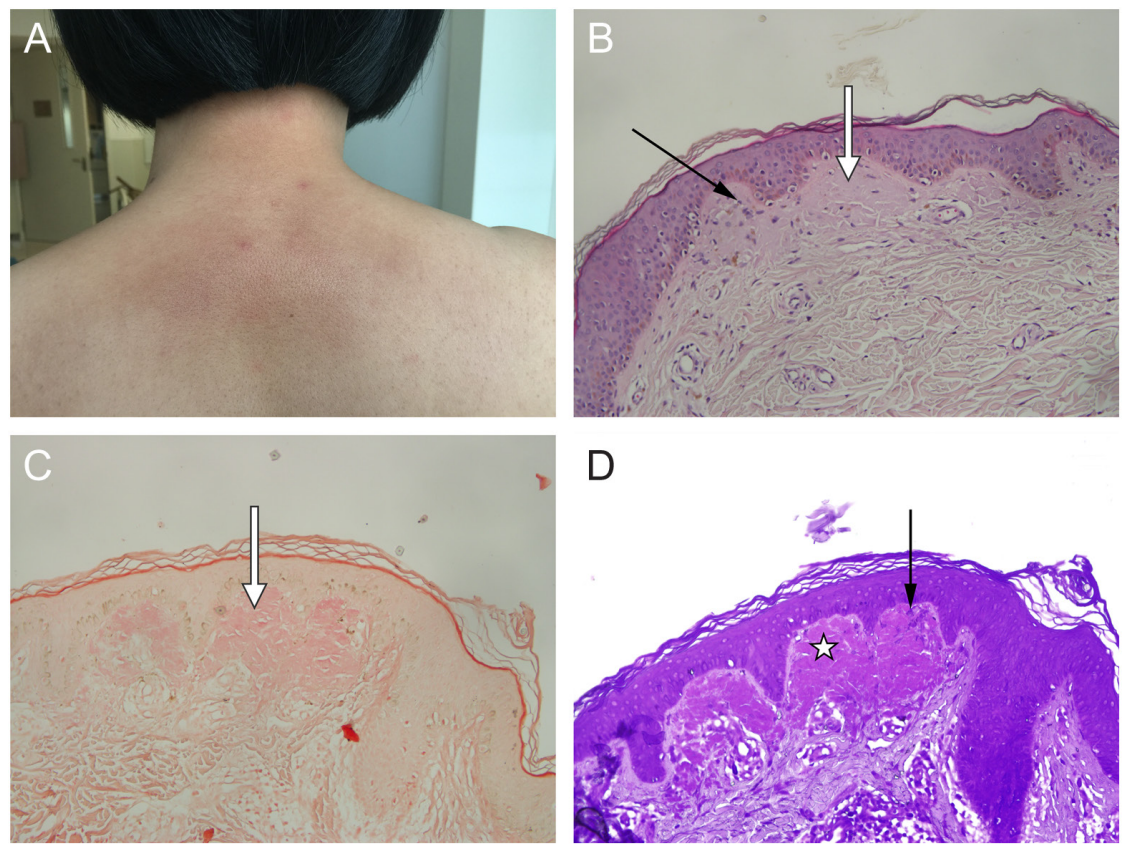

\section{Figure 2}

Clinical and histological presentation of MEN 2A-related CLA caused by the RET C611Y mutation. (A) Clinical characteristics of cutaneous lichen amyloidosis (CLA). Brown

hyperpigmentation, scaly, dry and thickened papular skin with scabby scratches on the interscapular region (individual III:12). (B, C and D) Histopathological features of CLA. (B) A skin biopsy of lesional skin reveals overlying epidermal orthokeratotic hyperkeratosis, irregular acanthosis and eosinophilic deposits of amorphous material (white arrow) in the papillary dermis. Numerous scattered melanophages (black arrow) and small amounts of an amorphous material just below the dermoepidermal junction can be observed in the upper dermis (haematoxylin-eosin; original magnification, $\times 200$ ). (C) The papillary dermal globular deposits of amyloid were positive for Congo red stain (white arrow; original magnification, $\times 200$ ). (D) The papillary dermal globular deposits of amyloid were positive for crystal violet staining (white asterisk) and overlying pigmentary incontinence (black arrow; original magnification, $\times 200$ ).

\section{Other MEN2-associated diseases and surgical outcome}

All 17 affected individuals presented no evidence of HPT, Hirschsprung disease, corneal nerve thickening or other endocrine tumors through screening of serum calcium, PTH, slit lamp examination and other relevant imaging examination. Of these, 13 underwent thyroid and/or adrenal gland surgery. After the latest surgery, all 13 attained normal Ctn (biochemical cure), except 5 individuals (4 of thyroid repeat procedure (III:1, III:7, III:10 and III:14); 1 of initial thyroid surgery (II:11)) who exhibited slightly elevated Ctn. In addition, 2 individuals (II:7 and III:12) underwent right adrenal-sparing surgery and have exhibited no recurrence thus far (Table 1). All 13 individuals needed individualized thyroid hormone replacement therapy. Furthermore, one (III:6) still rejected operation and further examination, and the other three individuals (IV:6, IV:7 and IV:15) still selected a watchful waiting approach (Table 1).

\section{Identification of the RET germline mutations}

The direct sequencing method confirmed a heterozygous nucleotide substitution in exon 10 of RET designated c. $1832 \mathrm{G}>\mathrm{A}$ in the proband (III:1) and other 16 subjects (II:3, II:6, II:7, II:11, III:6, III:7, III:10, III:12, III:14, III:21, III:24, IV:1, IV:5, IV:6, IV:7 and IV:15). This variant substitutes the corresponding amino acid cysteine to tyrosine in codon 611, designated C611Y, which targets one of five cysteine residues in the extracellular domain of RET. Furthermore, we discovered five recurrent exonic polymorphisms of c.135A>G (p.A45A), c.1296A>G (p.A432A), c.2071G>A (p.G691S), c.2307T>G (p.L769L) and c. $2712 \mathrm{C}>\mathrm{G}$ (p.S904S) respectively within exon 2, 7, 11, 13 and 15 (data not shown).

\section{Discussion}

This study demonstrated a recurrent RET C611Y mutation in a large south-eastern Chinese family with MEN 2A-related MTC and PHEO. Remarkably, CLA was also present in our patient and first manifested in the RET C611Y mutation. Thus, CLA should be one of the clinical manifestations of the RET C611Y mutation, which implies a novel genotype-phenotype relationship in MEN 2A.

The genotype-phenotype relationship between CLA and the RET mutation has been discussed previously $(1,2,4,5,6,7,8,23,24,25,26)$. Eng et al. (2) reported that CLA was detected in approximately 9\% (18/199) of patients with MEN 2A, and all 18 families carried RET codon 634 mutations. Verga et al. (23) reported that CLA was found in 3 of 10 MEN 2A/FMTC families with codon 634 mutation, and 9 of 25 affected subjects (36\%) with presented CLA, other 2 of them (8\%) lacked CLA skin lesions but the symptom of neurological pruritus in the upper back. Recently, accumulating evidence suggested that CLA in the scapular region occurred in $45.1 \%$ (55/122) of 122 RET carriers in 20 MEN2 families with CLA. http://www.endocrineconnections.org https://doi.org/10.1530/EC-18-0220
C) 2018 The authors Published by Bioscientifica Ltd
This work is licensed under a Creative Commons Attribution-NonCommercial-NoDerivatives 4.0 International License. 
The leading mutation at codon 634 in exon 11 (98.2\%, 54/55) was a C634Y mutation, followed by C634R/W/G/F and C634. Notably, only one V804M mutation in exon 14 was involved $(1.8 \%, 1 / 55)(7,8)$. The mean age at diagnosis of CLA with the RET mutation was 29.5 (range, 5-60) years, and in 51 individuals with CLA, the presence of MTC, PHEO and HPT was approximately 96.1\% $(49 / 51), 47.1 \%(24 / 51)$ and $13.7 \%$ (7/51), respectively (7). However, to date, no family with MEN2B has been reported to be diagnosed with CLA, as well as families with CLA, but without MEN2 disease features, do not have RET mutations $(2,4,5,6,7,27,28)$. In addition, an unexpected finding revealed that the gender-related predominance in the prevalence of CLA was observed as suggested by the male-to-female ratio of approximately 1.0:3.6 (12:43) (7).

In our family, of the 17 RET C611Y mutation carriers, only one female patient developed CLA after 18 years of itching and scratching (Table 1). CLA in patients with MEN 2A might be neglected because the skin lesion could not result in a definitive diagnosis $(7,22,24,29,30)$. Most patients with MEN 2A, including our patient, present with pruritic symptoms of CLA, which occurs before the onset of clinically evident MTC and PHEO (5, 7, 8, 22, 24, 29, $30)$. Nonetheless, the evolution of CLA might represent independently of the clinical disease course, which is not related to MEN 2A-related endocrine tumors such as MTC, PHEO or HPT (not correlated with increased levels of Ctn, metanephrines or PTH) $(7,8,22,23,30)$. Notably, not all family members with the RET mutation develop CLA. MEN 2A-related CLA in our kindred presented a much lower penetrance $(5.9 \%)$, although its result revealed in another patient with CLA-suspected clinical symptoms $(5.9 \%)$ in our study. Individuals with same or different RET mutation typically presented with a variable clinical manifestation of CLA, especially a diverse evident in the scapular region of the upper back, exhibiting on the side, midline or bilateral extending across the midline, followed by hyperpigmentation and then papules developed in the same area after many years of itching and scratching $(6,7$, $8,23)$. Conversely, previously reported cutaneous biphasic amyloidosis encompassing the upper back, shoulders, arms and legs harbored the RET S891A mutation and OSMR variant G513D in a Chinese FMTC family (9), whereas MEN 2A-related CLA was strictly located in the scapular region and had the RET C634F/G mutation without OSMR mutation in four Chinese patients (7). Only a small proportion of kindred develop this manifestation, and despite a sensory neuropathy, secondary scratching or other modifying factors involved have been suggested, but there is a lack of RET polymorphisms $(5,6,7,23)$.
However, the underlying molecular mechanism remains elusive. Diagnostically, the histology-based definition of MEN 2A-related CLA should result in an apparent delineation of skin lesions for localized amyloid. However, it would be prudent to treat these cases conservatively, and the treatment of CLA in MEN 2A remains disappointing to date $(4,5,6,7,31)$. Nonetheless, CLA in MEN 2A could be a relatively early clinical marker, as a characteristic of the clinical phenotype in 'MEN 2A with CLA', one of four variants of MEN 2A (5). Furthermore, CLA located in the scapular region is highly suggestive of MEN 2A, which should be investigated clinically, followed by germline RET screening $(4,5)$. Thus, CLA and MEN 2A in this individual should be attributed to the germline RET C611Y mutation rather than a coincidental situation, similar to a V804M mutation with CLA and MTC $(5,8)$.

The RET C611Y mutation comprising c.1832G $>\mathrm{A}$ and c.1832_1833delinsAT exhibited the typical presentation of classical MEN 2A or FMTC, and occur at a 'moderate risk' (ATA-MOD) form of disease $(4,5,10,11,12,13,14$, $15,16,17,18,19)$. In our kindred, all 17 affected patients (except 3 carriers (IV-6, IV-7 and IV-15)) presented with MTC or elevated serum calcitonin levels (82.4\%). The mean age of patients was 45.9 (range: 23-73) years; two of them $(11.8 \%$ ) had unilateral PHEO (mean age, 53 (range: 37-73) years; Table 1). The clinical data in this family might imply the clinical pattern of a later diagnosis/onset of MTC and a lower penetrance of PHEO. Nonetheless, the genetic $R E T$ screening can instructively classify the pathology of thyroid tumors, and individuals with C611Y should be managed using a personalized approach and be related to psychological support $(5,32,33,34,35,36,37,38,39,40)$.

In summary, this study highlights a novel genotypephenotype relationship between MEN 2A-related CLA and C611Y mutation of RET. CLA located in the interscapular region might represent earlier and 'premonitory' symptom should facilitate the early recognition of individuals at risk of MEN 2A-specific tumors. Furthermore, the timing of total thyroidectomy in carriers with the RET C611Y mutation should be considered to use a personalized approach based on the Ctn level.

\section{Declaration of interest}

The authors declare that there is no conflict of interest that could be perceived as prejudicing the impartiality of the research reported.

\section{Funding}

This work was supported by the National Natural Science Foundation of China (81472861), the Key Project of Zhejiang Province Science and 
Technology Plan, China (2014C03048-1) and the Medical Science and Technology Project of Zhejiang Province, China (2014KYB219)

\section{Author contribution statement}

All authors were involved in the study. X-P Qi conceived and designed the experiments. X-P Qi, J-Z Peng, X-W Yang, Z-L Cao, X-H Yu, X-D Fang and J-Q Zhao performed the experiments; X-P Qi, J-Z Peng, D-H Zhang and J-Q Zhao analyzed the data; X-P Qi, X-W Yang, Z-L Cao and J-Q Zhao contributed reagents/materials/analysis tools. The manuscript was written by X-P Qi.

\section{Acknowledgements}

The authors thank all the patients and the family who agreed to participate in this study.

\section{References}

1 Ceccherini I, Romei C, Barone V, Pacini F, Martino E, Loviselli A, Pinchera A \& Romeo G. Identification of the Cys634-->Tyr mutation of the RET proto-oncogene in a pedigree with multiple endocrine neoplasia type 2A and localized cutaneous lichen amyloidosis. Journal of Endocrinological Investigation 199417 201-204. (https://doi. org/10.1007/BF03347719)

2 Eng C, Clayton D, Schuffenecker I, Lenoir G, Cote G, Gagel RF, van Amstel HK, Lips CJ, Nishisho I, Takai SI, et al. The relationship between specific RET proto-oncogene mutations and disease phenotype in multiple endocrine neoplasia type 2. International RET mutation consortium analysis. JAMA 1996276 1575-1579. (https:// doi.org/10.1001/jama.1996.03540190047028)

3 Kloos RT, Eng C, Evans DB, Francis GL, Gagel RF, Gharib H, Moley JF, Pacini F, Ringel MD, Schlumberger M, et al. Medullary thyroid cancer: management guidelines of the American Thyroid Association. Thyroid 200919 565-612. (https://doi.org/10.1089/ thy.2008.0403)

4 Elisei R, Alevizaki M, Conte-Devolx B, Frank-Raue K, Leite V \& Williams GR. 2012 European thyroid association guidelines for genetic testing and its clinical consequences in medullary thyroid cancer. European Thyroid Journal 20131 216-231. (https://doi. org/10.1159/000346174)

5 Wells SA Jr, Asa SL, Dralle H, Elisei R, Evans DB, Gagel RF, Lee N, Machens A, Moley JF, Pacini F, et al. Revised American Thyroid Association guidelines for the management of medullary thyroid carcinoma. Thyroid 201525 567-610. (https://doi.org/10.1089/ thy.2014.0335)

6 Scapineli JO, Ceolin L, Punales MK, Dora JM \& Maia AL. MEN 2A-related cutaneous lichen amyloidosis: report of three kindred and systematic literature review of clinical, biochemical and molecular characteristics. Familial Cancer 201615 625-633. (https://doi. org/10.1007/s10689-016-9892-6)

7 Qi XP, Zhao JQ, Cao ZL, Fu E, Li F, Zhao YH, Wang GP, Li PF, Ma WL, Guo J, et al. The clinical spectrum of multiple endocrine neoplasia type 2A with cutaneous lichen amyloidosis in Ethnic Han Chinese. Cancer Investigation 201836 141-151. (https://doi.org/10.1080/07357 907.2018.1430813)

8 Rothberg AE, Raymond VM, Gruber SB \& Sisson J. Familial medullary thyroid carcinoma associated with cutaneous lichen amyloidosis. Thyroid 200919 651-655. (https://doi.org/10.1089/thy.2009.0021)

9 Qi XP, Zhao JQ, Chen ZG, Cao JL, Du J, Liu NF, Sheng M, Fu E, Guo J, Jia $\mathrm{H}$, et al. RET mutation p.S891A in a Chinese family with familial medullary thyroid carcinoma and associated cutaneous amyloidosis binding OSMR variant p.G513D. Oncotarget 20156 33993-34003. (https://doi.org/10.18632/oncotarget.4992)
10 Mulligan LM, Eng C, Healey CS, Clayton D, Kwok JB, Gardner E, Ponder MA, Frilling A, Jackson CE, Lehnert H, et al. Specific mutations of the RET proto-oncogene are related to disease phenotype in MEN 2A and FMTC. Nature Genetics 19946 70-74. (https://doi.org/10.1038/ng0194-70)

11 Landsvater RM, Jansen RP, Hofstra RM, Buys CH, Lips CJ \& Ploos van Amstel HK. Mutation analysis of the RET proto-oncogene in Dutch families with MEN 2A, MEN 2B and FMTC: two novel mutations and one de novo mutation for MEN 2A. Human Genetics 199697 11-14. (https://doi.org/10.1007/BF00218825)

12 Wohllk N, Cote GJ, Bugalho MM, Ordonez N, Evans DB, Goepfert H, Khorana S, Schultz P, Richards CS \& Gagel RF. Relevance of RET proto-oncogene mutations in sporadic medullary thyroid carcinoma. Journal of Clinical Endocrinology and Metabolism 199681 3740-3745. (https://doi.org/10.1210/jcem.81.10.8855832)

13 Hansen HS, Torring H, Godballe C, Jäger AC \& Nielsen FC. Is thyroidectomy necessary in RET mutations carriers of the familial medullary thyroidcarcinoma syndrome? Cancer 20009 863-867. (https://doi.org/10.1002/1097-0142(20000815)89:4<863::AIDCNCR19>3.0.CO;2-Z)

14 Bahlo M, Schott M, Kaminsky E \& Cupisti K. Multiple endocrine neoplasia 2a: late manifestation of a newly-discovered mutation. Deutsche medizinische Wochenschrift 2008133 464-466. (https://doi. org/10.1055/s-2008-1046733)

15 Frank-Raue K, Rybicki LA, Erlic Z, Schweizer H, Winter A, Milos I, Toledo SP, Toledo RA, Tavares MR, Alevizaki M, et al. Risk profiles and penetrance estimations in multiple endocrine neoplasia type 2A caused by germline RET mutations located in exon 10. Human Mutation 201132 51-58. (https://doi.org/10.1002/humu.21385)

16 Korpershoek E, Petri BJ, Post E, van Eijck CH, Oldenburg RA, Belt EJ, de Herder WW, de Krijger RR \& Dinjens WN. Adrenal medullary hyperplasia is a precursor lesion for pheochromocytoma in MEN2 syndrome. Neoplasia 201416 868-873. (https://doi.org/10.1016/j. neo.2014.09.002)

17 Yeganeh MZ, Sheikholeslami S, Dehbashi Behbahani G, Farashi S \& Hedayati M. Skewed mutational spectrum of RET proto-oncogene Exon10 in Iranian patients with medullary thyroid carcinoma. Tumour Biology 201536 5225-5231. (https://doi.org/10.1007/s13277015-3179-7)

18 Liu Q, Tong D, Yuan W, Liu G, Yuan G, Lan W, Zhang D, Zhang J, Huang Z, Zhang Y, et al. Different RET gene mutation-induced multiple endocrine neoplasia type 2A in 3 Chinese families. Medicine 201796 e5967. (https://doi.org/10.1097/MD.0000000000005967)

19 Mathiesen JS, Kroustrup JP, Vestergaard P, Stochholm K, Poulsen PL, Rasmussen Å, Feldt-Rasmussen U, Gaustadnes M, Ørntoft TF, van Overeem Hansen T, et al. Distribution of RET mutations in multiple endocrine neoplasia 2 in Denmark 1994-2014: a nationwide study. Thyroid 201727 215-223. (https://doi.org/10.1089/thy.2016.0411)

20 Qi XP, Chen XL, Ma JM, Du ZF, Fei J, Yang CP, Cheng J, Song QZ, Han JS, Jin HY, et al. RET proto-oncogene genetic screening of families with multiple endocrine neoplasia type 2 optimizes diagnostic and clinical management in China. Thyroid 201222 1257-1265. (https://doi.org/10.1089/thy.2012.0134)

21 Edge SB \& Compton CC. The American Joint Committee on Cancer: the 7th edition of the AJCC cancer staging manual and the future of TNM. Annals of Surgical Oncology 201017 1471-1474. (https://doi. org/10.1245/s10434-010-0985-4)

22 Karga HJ, Karayianni MK, Linos DA, Tseleni SC, Karaiskos KD \& Papapetrou PD. Germ line mutation analysis in families with multiple endocrine neoplasia type $2 \mathrm{~A}$ or familial medullary thyroid carcinoma. European Journal of Endocrinology 1998139 410-415. (https://doi.org/10.1530/eje.0.1390410)

23 Verga U, Fugazzola L, Cambiaghi S, Pritelli C, Alessi E, Cortelazzi D, Gangi E \& Beck-Peccoz P. Frequent association between MEN 2A and cutaneous lichen amyloidosis. Clinical Endocrinology 200359 156-161. (https://doi.org/10.1046/j.1365-2265.2003.01782.x) 
24 Abdullah F \& Udelsman R. Cutaneous lichen amyloidosis in a family with familial medullary thyroid cancer. Surgery 2004135 563-564. (https://doi.org/10.1016/S0039)

25 Hofstra RM, Sijmons RH, Stelwagen T, Stulp RP, Kousseff BG, Lips CJ, Steijlen PM, Van Voorst Vader PC \& Buys CH. RET mutation screening in familial cutaneous lichen amyloidosis and in skin amyloidosis associated with multiple endocrine neoplasia. Journal of Investigative Dermatology 1996107 215-218. (https://doi. org/10.1111/1523-1747.ep12329651)

26 Gullu S, Gursoy A, Erdogan MF, Dizbaysak S, Erdogan G \& Kamel N. Multiple endocrine neoplasia type 2A/localized cutaneous lichen amyloidosis associated with malignant pheochromocytoma and ganglioneuroma. Journal of Endocrinological Investigation 200528 734-737. (https://doi.org/10.1007/BF03347557)

27 Lee DD, Huang JY, Wong CK, Gagel RF \& Tsai SF. Genetic heterogeneity of familial primary cutaneous amyloidosis: lack of evidence for linkage with the chromosome 10 pericentromeric region in Chinese families. Journal of Investigative Dermatology $1996 \mathbf{1 0 7}$ 30-33. (https://doi.org/10.1111/1523-1747.ep12297840)

28 Arita K, South AP, Hans-Filho G, Sakuma TH, Lai-Cheong J, Clements S, Odashiro M, Odashiro DN, Hans-Neto G, Hans NR, et al. Oncostatin $\mathrm{M}$ receptor-beta mutations underlie familial primary localized cutaneous amyloidosis. American Journal of Human Genetics 200882 73-80. (https://doi.org/10.1016/j.ajhg.2007.09.002)

29 Seri M, Celli I, Betsos N, Claudiani F, Camera G \& Romeo G. A Cys634Gly substitution of the RET proto-oncogene in a family with recurrence of multiple endocrine neoplasia type $2 \mathrm{~A}$ and cutaneous lichen amyloidosis. Clinical Genetics 199751 86-90. (https://doi. org/10.1111/j.1399-0004.1997.tb02425.x)

30 Birla S, Singla R, Sharma A \& Tandon N. Rare manifestation of multiple endocrine neoplasia type $2 \mathrm{~A} \&$ cutaneous lichen amyloidosis in a family with RET gene mutation. Indian Journal of Medical Research 2014139 779-781.

31 Anitha B \& Mysore V. Lichen amyloidosis: novel treatment with fractional ablative 2,940 $\mathrm{nm}$ erbium: YAG laser treatment. Journal of Cutaneous and Aesthetic Surgery 20125 141-143. (https://doi. org/10.4103/0974-2077.99459)

32 Elisei R, Romei C, Renzini G, Bottici V, Cosci B, Molinaro E, Agate L, Cappagli V, Miccoli P, Berti P, et al. The timing of total thyroidectomy in RET gene mutation carriers could be personalized and safely planned on the basis of serum calcitonin: 18 years experience at one single center. Journal of Clinical Endocrinology and Metabolism 201297 426-435. (https://doi.org/10.1210/jc.2011-2046)

33 Qi XP, Zhao JQ, Du ZF, Yang RR, Ma JM, Fei J, Cheng J, Han JS, Jin HY, Chen ZG, et al. Prophylactic thyroidectomy for MEN 2-related medullary thyroid carcinoma based on predictive testing for RET proto-oncogene mutation and basal serum calcitonin in China. European Journal of Surgical Oncology 201339 1007-1012. (https://doi. org/10.1016/j.ejso.2013.06.015)

34 Pelizzo MR, Torresan F, Boschin IM, Nacamulli D, Pennelli G, Barollo S, Rubello D \& Mian C. Early, prophylactic thyroidectomy in hereditary medullary thyroid carcinoma: a 26-year monoinstitutional experience. American Journal of Clinical Oncology 201538 508-513. (https://doi.org/10.1097/COC.0b013e3182a78fec)

35 Machens A \& Dralle H. Advances in risk-oriented surgery for multiple endocrine neoplasia type 2. Endocrine-Related Cancer 201825 T41-T52. (https://doi.org/10.1530/ERC-17-0202)

36 Grey J \& Winter K. Patient quality of life and prognosis in multiple endocrine neoplasia type 2. Endocrine-Related Cancer 201725 T69-T77. (https://doi.org/10.1530/ERC-17-0335)

37 Machens A, Elwerr M, Lorenz K, Weber F \& Dralle H. Long-term outcome of prophylactic thyroidectomy in children carrying RET germline mutations. British Journal of Surgery 2018105 e150-e157. (https://doi.org/10.1002/bjs.10746)

38 Moodley S, Weber F \& Mulligan LM. The evolving clinical, genetic and therapeutic landscape of multiple endocrine neoplasia type 2 . Endocrine-Related Cancer 201825 E1-E4. (https://doi.org/10.1530/ ERC-17-0488)

39 Castinetti F, Qi XP, Walz MK, Maia AL, Sansó G, Peczkowska M, Hasse-Lazar K, Links TP, Dvorakova S, Toledo RA, et al. Outcomes of adrenal-sparing surgery or total adrenalectomy in phaeochromocytoma associated with multiple endocrine neoplasia type 2: an international retrospective population-based study. Lancet Oncology 201415 648-655. (https://doi.org/10.1016/S14702045(14)70154-8)

40 Machens A, Lorenz K, Weber F \& Dralle H. Genotype-specific progression of hereditary medullary thyroid cancer. Human Mutation 201839 860-869. (https://doi.org/10.1002/humu.23430)
Received in final form 18 July 2018

Accepted 24 July 2018

Accepted Preprint published online 26 July 2018 http://www.endocrineconnections.org https://doi.org/10.1530/EC-18-0220 (c) 2018 The authors Published by Bioscientifica Ltd

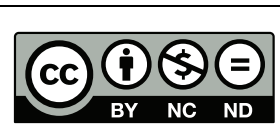

This work is licensed under a Creative Commons Attribution-NonCommercial-NoDerivatives 4.0 International License. 